\title{
Heavy Grazing Reduces the Diversity of Soil Microbial Communities in Meadow Grassland Under Long-Term Grazing
}

Yu Zhang

CAAS IARRP: Chinese Academy of Agricultural Sciences Institute of Agricultural Resources and Regional Planning https://orcid.org/0000-0002-9695-0937

Xiaoping Xin

CAAS IARRP: Chinese Academy of Agricultural Sciences Institute of Agricultural Resources and Regional Planning

Ruiqiang Li

Enviromental Online Moitoring Center of Inner Monglia

Weibing Xun

Nanjing Agricultural University

Ruifu Zhang

CAAS IARRP: Chinese Academy of Agricultural Sciences Institute of Agricultural Resources and Regional Planning

Linghao Li

Institute of Botany Chinese Academy of Sciences

Xu Wang

CAAS IARRP: Chinese Academy of Agricultural Sciences Institute of Agricultural Resources and Regional Planning Jinqiang Chen

CAAS IARRP: Chinese Academy of Agricultural Sciences Institute of Agricultural Resources and Regional Planning Ruirui Yan ( $\square$ yanruirui19790108@163.com)

CAAS IARRP: Chinese Academy of Agricultural Sciences Institute of Agricultural Resources and Regional Planning https://orcid.org/0000-0002-9400-1105

\section{Research}

Keywords: Hulun Buir grassland, grazing intensity, soil microorganisms, Inner Mongolia, meadow steppe

Posted Date: December 17th, 2020

DOl: https://doi.org/10.21203/rs.3.rs-129099/v1

License: @ (1) This work is licensed under a Creative Commons Attribution 4.0 International License. Read Full License 


\section{Abstract}

Background: Soil microorganisms are an important part of the grassland ecosystem and promote material transformation and energy flow in the entire ecological environment. Moreover, Hulun Buir grassland is the material basis for the development of animal husbandry. Therefore, it is of great scientific significance to study the changes of soil microbial community caused by grazing in Hulunbuir grassland for the sustainable and stable development of grassland ecosystem.

Methods: The present research used high-throughput sequencing of soil microorganism (bacteria and fungi) genes to compare microbial communities in 6 levels of grazing intensity $\left(0.00,0.23,0.34,0.46,0.69\right.$, and $\left.0.92 \mathrm{Au} \mathrm{ha}^{-1}\right)$ under the Hulun Buir structure and the diversity characteristics of Leymus chinensis meadow steppe.

Results: The 0-10 cm soil layer of the G0.34 test area had the highest content, and the content of the G0.92 test area was lower than the other grazing treatments. With increasing depth, the carbon and nitrogen contents of microorganisms decreased. The diversity of soil bacteria in the light grazing test area $\left(0.23 \mathrm{Au} \mathrm{ha}^{-1}\right)$ was higher than the heavy grazing area, and the diversity of fungi in the non-grazing area was higher than the specific grazing areas. Most bacterial species were enriched in the $\mathrm{G} 0.00$ grazing areas, and the other grazing intensities were less abundant. The underground biomass $(P=0.039)$ significantly influenced the bacterial community structure, and $\mathrm{pH}(\mathrm{P}=0.032)$, total nitrogen $(\mathrm{P}=0.011)$ and litter $(\mathrm{P}=0.007)$ significantly influenced the fungal community.

Conclusions: In conclusion, the structures of bacterial and fungal communities are very sensitive to grazing and varied with grazing intensity. Our findings demonstrated that a grazing intensity of approximately $0.23 \mathrm{Au} \mathrm{ha}^{-1}$ was the most appropriate for the grassland of the meadow in Hulun Buir.

\section{Introduction}

Soil microorganisms are largest underground repository of grassland ecosystems and play an important role in the grassland ecological system in the promotion of the flow of material and energy transfer in the entire environment and the maintenance of the grassland ecological system [1]. Soil microorganisms are extremely sensitive to changes of environment [2]. Grazing is the main use of grassland ecological systems [3], and long-term unreasonable grazing affects the vegetation community structure and soil characteristics [4-6], which change the soil microbial community. Changes in the soil microbial community structure affect the vegetation in the community, which impacts the entire ecosystem [7]. Soil microbial diversity is an important index for evaluations of community characteristics and stability, which reflect the functional evolution of ecosystems and environmental changes. In general, greater microbial diversity indicates stronger soil biological activity, which is more conducive to plant growth [8]. Therefore, it is of great significance to examine the relationship between different grazing intensities and microbial community structure and diversity of grassland and soil and vegetation characteristics to reveal the mechanisms of succession direction of grazing grasslands.

To perform clear and reasonable grazing management of grasslands, increasing studies were performed in recent years on the impact of grazing on the soil microbial community, including soil microbial number [9], soil microbial quantity [10], soil microbial enzyme activity [11], soil microbial community structure [12] and soil microbial diversity [13]. These studies showed that light grazing significantly increased the soil microbial population and microbial biomass [14], but overgrazing reduced the soil microbial biomass carbon [15]. Moderate grazing changed the living environment of soil microorganisms, which was conducive to their growth [16], improved microbial diversity, changed the microbial community structure, improved soil quality and maximized grassland productivity [17]. Zhalnina et al. [18] found that soil pH determined microbial diversity and composition, and bacterial diversity was higher in neutral soil and weakly acidic soil. Sun Yifei et al. [19] showed that changes in usable nitrogen content caused by grazing led to significant changes in ammonia-oxidizing microbial community structure. Xun et al. [20] showed that grazing changed the microbial composition of meadow grasslands from slow-growing and fungi to fast-growing and bacteria-dominated communities. For the Qinghai-Tibet Plateau, the research results showed that soil bacterial diversity was the highest in moderate grazing areas, and the migration of soil bacterial diversity grazing changed [21-23]. Grazing may affect the distribution of alpine grassland microorganisms on a small spatial scale and changed the impact of water on the microbial community [24]. These results also reflect the inconsistent response mode of soil microorganisms to grazing due to different geographical locations and seasonal climate [25-26], the complex relationship between grazing and soil microorganisms, and different changing trends under the influence of environmental factors.

As an important part of the Eurasian steppe, Hulunbuir steppe is an important material basis for the development of animal husbandry and the basic means of production for the survival of farmers and herdsmen. Therefore, to study the relationship between grazing and microorganisms in this region and establish a reasonable grazing system is vital importance. In this study, high-throughput sequencing was used to sequence some bacterial 16S R RNA and fungal $18 \mathrm{~S}$ RNA genes, to evaluate the structure of soil microbial community under six grazing intensities. The microbial biomass carbon and nitrogen and soil physical and chemical properties were measured under different grazing intensities. The objectives of this study were to investigate grazing-induced changes in the composition, diversity, microbial biomass carbon and nitrogen, and their interaction with the physical and chemical properties of vegetation and soil.

\section{Materials And Methods Study site and sampling}

The research area is located in the Inner Mongolia Autonomous Region, China. The experiment was based on the National Field Scientific Observation and Research Station of Hulun Buir Grassland Ecosystem (N $49^{\circ} 19^{\prime} 349$ " 49²0' 173", E $119^{\circ} 56$ '521 " 11957' 854 ", altitude of $666 \sim 680$ m), which is a temperate semi-arid continental climate. The average annual temperature is $-5 \sim-2^{\circ} \mathrm{C}$, with the highest and lowest temperatures of $21.1^{\circ} \mathrm{C}$ and $-27.2^{\circ} \mathrm{C}$, respectively. The average annual precipitation is $350 \sim 400 \mathrm{~mm}$, and the highest precipitation periods are from July to September (Fig. 1). The soil types of the 
study sites were or chestnut soil, which corresponds to Castanozems in the soil taxonomic system of FAO and the calcic-orthic aridosol in the US soil classification system. The study regionalization was divided into 6 grazing areas with different grazing intensities, $0.00,0.23,0.34,0.46,0.69$, and 0.92 Au ha

${ }^{1}$, named G0.00, G0.23, G0.34, G0.46, G0.69 and G0.92, respectively. For grazing, 500-kg beef cattle was used as the standard cattle beef unit (Fig. 2). Each grazing intensity was divided into three repetitions, and each plot area was $5 \mathrm{ha}^{-1}$. Since 2009, grazing began on June 1 st and stopped on October 1 st each year for 120 days. Samples were collected in the 10th year of grazing treatment. Soil samples were collected in August 2018 to determine the microbial community structure and soil physical and chemical properties and investigate the characteristics of the plant community.

Five quadrats $(1 \times 1 \mathrm{~m})$ in each test area were randomly selected to measure the height, coverage and density of plants in each quadrat, and the aboveground parts of plants in the quadrat were divided and cut using the method of cutting the whole ground. Plants were put in a sample bag, numbered and transported to the laboratory. The fresh weight was measured, and plants were dried in a paper bag under a constant temperature $\left(85^{\circ} \mathrm{C}\right)$ for $12 \mathrm{~h}$. The dry weight was measured, and the aboveground biomass of the community was calculated. The underground biomass of community was determined using the excavation method of 5 topsoil samples (0-10 cm depth) that were randomly selected from each quadrat and immediately mixed into a single soil sample. Rocks and animal and plant residues were removed from the soil for the determination of soil chemical properties, soil physical properties, bacteria and fungi, microbial carbon and nitrogen.

\section{Determination of Physical and Chemical Properties of the Soil}

A specific method was used to determine the soil chemical properties that was different from the instrument instructions. Soil temperatures (ST) of the $0-$ $10 \mathrm{~cm}$ soil layers were measured by portable thermometers that can be inserted down to different soil depths when collecting soil samples that need to determine the soil microbial community,and three replicate soil samples of each test area $(0-10 \mathrm{~cm}$ soil layers) were collected Simultaneously. Soil moisture (SM) was measured by the oven-drying method, and the gravimetric soil water content was determined by drying the sampled soil at $105^{\circ} \mathrm{C}$ for $24 \mathrm{~h}$. Soil $\mathrm{pH}$ was measured in a 1:2.5 soil/water mixture by a multi-parameter water quality analyser. Soil total nitrogen (TN) concentration was measured the semi-micro Kjeldahl determination. The dichromate oxidation and sodium hydroxide alkali-molybdenum-antimony colorimetric methods were used to determine the soil organic carbon (SOC) concentration, and soil total phosphorus (TP) concentration. A spectrophotometer was used to measure soil total potassium (TK) concentration, soil available phosphorus (SAP) concentration and soil available potassium (SAK) concentration. Soil ammonium nitrogen and nitrate nitrogen $\left(\mathrm{NH}_{4}{ }^{+}-\mathrm{N}\right.$ and $\left.\mathrm{NO}_{3}{ }^{-} \mathrm{N}\right)$ were determined using a flow injection auto-analyzer (FIAstar 5000 Analyzer, Foss Tecator, Denmark). Soil microbial biomass carbon (MBC) and nitrogen (MBN) were measured using fumigation-volumetric analysis and the fumigation-ninhydrin colorimetric method, respectively.

\section{DNA collection and high-throughput sequencing}

Genomic DNA was isolated from $0.5 \mathrm{~g}$ of each pooled soil sample from each sample plot $(\mathrm{n}=36)$ using the Power Soil DNA Isolation Kit (Mo Bio Laboratories, Solana Beach, CA, USA) per the manufacturer's instructions. The extracts of three technical repeats were mixed into a single DNA sample. Extracted genomic DNA was detected using 1\% agarose gel electrophoresis. PCR was carried out on a Gene Amp 9700 PCR system (Applied Biosystems, Foster City, CA, USA). Based previous reports, the primers (Biosciences, Union City, CA, USA) were washed with Tris- $\mathrm{HCl}$ and verified using $2 \%$ agarose gel electrophoresis. PCR products were quantified using the Quanti Fluor TMs 338F-806R [27] and 817F-1196R [28] for the 16S rRNA and 18SrRNA genes, respectively. Amplified products were detected using $2 \%$ agarose gel electrophoresis and recovered from the gel using the Axy Prep DNA gel extraction kit (Axygen -ST Fluorometer, Promega Biotech, Beijing, China), and the samples were adjusted as needed for sequencing. Sequencing was performed by Shanghai Majorbio Bio-pharm Technology (Shanghai, China) using an Illumina MiSeq platform (San Diego, CA, USA).

\section{Statistical analysis}

One-way ANOVA of soil physical and chemical properties was performed using SPSS 21.0. Significance was calculated using Tukey's test ( $P<0.05)$. Origin 2017 was used for figures of MBC and MBN. The relationship between soil microbial community structure and each affecting factor was analysed using RDA and variation partitioning. RDA eliminates redundant variables depending on the other measured variables (variables with large effects are and automatically selected) and on the variance inflation factor values to gradually remove redundant parameters, and the significance levels are based on 999 Monte Carlo permutations. Linear discriminant analysis (LDA) coupled with effect size measurements (LEfSe) analysis was performed to search for significantly different biomarkers between groups [29].

\section{Results}

\section{Soil and vegetation characteristics change under different grazing intensities}

As can be seen from Table 1, the changes of soil physical and chemical properties under different grazing intensities were as follows: SM was significantly reduced with the increase of grazing intensities $(P<0.05)$, and the content of non-grazing plotd was the highest. N03-N was significantly higher than other grazing intensity in the $\mathrm{G} 0.69$ plot $(P<0.05)$, while other factors showed no significant difference under different grazing intensity. Vegetation characteristics showed significant differences under different grazing intensities $(P<0.05)$ (Table 1$)$ : BGB and Coverage of non-grazing and light grazing $(0.23,0.34)$ were significantly higher than middle and heavy grazing $(0.46,0.69)$. With the increase of grazing intensity, Litter decreased significantly, which was highest in the non-grazing treatment, with no litter at the moderate and severe levels $(0.46,0.69,0.92)$.

\section{Changes in the soil microbial biomass carbon and nitrogen under different grazing intensities}

Our results showed that the variation trends of microbial biomass carbon (MBC) and microbial biomass nitrogen (MBN) downstream of grazing treatment were the same (Fig. 3). The content in the G0.34 plots was the highest in the $0-10 \mathrm{~cm}$ soil layer, and the content in the G0.92 test plots was smaller than other 
grazing treatments. Except for the area with a grazing intensity of 0.34 , the greater the grazing intensity, the lower the MBC and MBN content. The G0.00 soil in soil layers $10-20 \mathrm{~cm}$ and $20-30 \mathrm{~cm}$ was higher than the other grazing intensities. The microbial carbon and nitrogen contents decreased with increasing depth. These results are consistent with the parallel and vertical distribution of microorganisms.

\section{Composition of microbial community under different grazing intensities Soil microbial diversity changes under different grazing intensities}

The soil microbial diversity indexes of the 6 grazing treatments are shown in Fig. 4. Coverage represents the proportion of the sequence obtained by sequencing of the whole genome. The Shannon index reflects the variation or difference degree of the microbial community, which was affected by the total number of samples and uniformity. Higher values indicate higher microbial community diversity in the soil[30]. The Chao index uses the chao1 algorithm to estimate the number of operational taxonomic units in samples. Chao1 is often used to estimate the total number of species in ecology. The coverage value of each sample was higher than 0.97 , which indicates that the sequence obtained by sequencing had a high coverage degree and good representativeness. This result reflects that the clone library constructed in this study represented the diversity of soil bacteria in this area.

The a diversity indexes of $\mathrm{G} 0.23$ and G0.34 bacteria were higher, and the a diversity indexes of G0.00 and G0.92 grasses were lower. These results are consistent with the intermediate disturbance hypothesis. The Chao of the fungus in the heavy grazing area was lower than the other treatments, but the diversity and uniformity of the fungal community was higher than the light grazing area.

\section{Microbial community structures in soils with different grazing intensities}

The histograms of dominant gates of soil bacteria and fungi (Fig. 5A and B) were obtained according to the rule that the proportion of microbial abundance was greater than $1 \%$. There were 10 species abundance ratios of bacteria greater than 0.01 , and the 10 dominant bacteria (abundance values greater than $1 \%$ ) detected in 6 different grazing treatments were Actinobacteria, Proteobacteria, Acidobacteria, Chloroflexi, Verrucomicrobia, Bacteroidetes, Gemmatimonadetes, Nitrospirae, Firmicutes, and Plancomycete. Among these bacteria, Chloroflexi differed significantly between different grazing intensities $(P<0.05)$, with the lowest Chloroflexi in non-grazing and heavy grazing intensities, and the highest amounts in a medium grazing area (G0.46). There were 4-5 phyla with fungal abundance values greater than 1\% in different grazing intensities: Ascomycota, Zygomycota, Unclassified_k_Fu, Basidiomycota, and Chytridiomycota. The abundance of Chytridiomycota was greater than $1 \%$ only in non-grazed (G0.00) and moderately grazed (G0.46) grasslands. Bacteria had different abundances across the 6 grazing intensities. Actinobacteria and Proteobacteria were the absolute dominant bacterial species. Ascomycota was the fungus phylum with dominant abundance values in the 6 treatments, and G0.46 was higher than the other treatments.

\section{Microbial communities with statistically significant differences}

Microbial communities with statistically significant differences were determined using $\alpha$ - and $\beta$-diversities. Another primary goal of comparing microbial communities was to identify specialized communities within the samples using the LEfSe tool. This tool allows analyses of microbial community data at any clade. Because the analysis of the large number of OTUs detected in the present study would be computationally too complex, statistical analysis was performed only from the domain to the genus level. Groups are shown in cladograms, and LDA scores of 2 or greater were confirmed using LEfSe (Fig. 6,7).

Most bacterial species were enriched in G0.00 and G0.69 and less abundant in the other grazing intensities (Fig. 6). Fifteen bacteria are enriched significantly in G0.00, including p_Bacteroidetes, o_Sphingobacteriales and c_Sphingobacteriia, which were the most important (LDA > 3.5). Four species of bacteria were significantly enriched in $\mathrm{G} 0.23$, and f_Burkholderiaceae was the most important (LDA = 3.5). There were 4 bacteria with significant enrichment in G0.34, of which o_norank_c_Gemmatimonadetes, g_norank_c_Gemmatimonadetes and f_norank_c_Gemmatimonadetes were the most important (LDA $=2.5)$. Three species of bacteria were significantly enriched in G0.46, and p_Chloroflexi was the most important (LDA > 4.0). Thirteen species of bacteria were significantly enriched in G0.69, and f_Roseiflexaceae, C_Chloroflexia, o_Chloroflexales and g_Roseiflexus were the most important (LDA > 3.0). Only g_Hymenobacter microbes were enriched significantly in G0.92 (LDA>2.5). Most fungal species were enriched in G0.00 and less enriched in the other grazing intensities (Fig. 7). Ten fungi were significantly enriched in G0.00 (Etes, o_unclassified_c_Lecanoromycetes, f_unclassified_c_Lecanoromycetes,

g_unclassified_c_Lecanoromycetes, g_unclassified_c_Orbiliomycetes, g_unclassified_c_Orbiliomycetes, and g_unclassified_cetes ), and

F_unclassified_CetesOrbiliomycetes was more important (LDA > 3.0). Only c_Wallemiomycetes was enriched significantly in G0.23 (LDA $>3.0)$. Three species of fungi were significantly enriched in G0.34, and g_Stilbella, f_Porotheleaceae and g_Porotheleum were more important $(2.5<$ LDA $<3)$. Two fungi were enriched significantly in G0.46, and g_Penicillium was the most important (LDA > 3.5). Two fungi were significantly enriched in G0.69, and g_unclassified_f_norank_o_Pleosporales was the most important (LDA>3.5). Two fungi were significantly enriched in G0.69, and g_Glitopilus was the most important (LDA>4.0).

\section{Relationship between microbial community structure and environmental characteristics Correlation between environmental factors and the microbial community}

Spearman correlation analysis was used to study the mutual changes between environmental factors and species and obtain the correlation and significance values between pair-wise comparisons. The bacteria and environmental parameters were significantly correlated (Fig. 8A). Norank_C_KD4-96 significantly positively correlated with $\mathrm{pH}$. Norank_cacidobacteria significantly positively correlated with SAP. Rubrobacter significantly negatively correlated with TP, and norank_o_Gaiellales significantly negatively correlated with BGB. Spearman correlation analysis showed the following significant correlations (Fig. 8B). Fusarium, Mortierella and SBD were significantly positively correlated $(P<0.05)$. Gibberella significantly correlated with SM $(P<0.05), \mathrm{SBD}(P<0.05)$, TK $(P<$ $0.01)$, NH4+ - N $(P<0.05)$, Mull $(P<0.001)$, and coverage $(P<0.01)$. These results showed a significant correlation between Penicillium and SM $(P<0.05), \mathrm{SBD}$ 
$(P<0.01)$ and TK $(P<0.05)$. Unclassified_Fasiosphaeriaceae significantly correlated with $\mathrm{SM}(\mathrm{P}<0.001)$, Mull $(P<0.01)$ and coverage $(P<0.05)$. There was a significant correlation between Unclassified_f__Nectriaceae and SBD $(P<0.05), \mathrm{TK}(P<0.05), \mathrm{NH}_{4}{ }^{+}-\mathrm{N}(P<0.05)$ and coverage $(P<0.05)$

\section{Environmental factors and the RDA of the microbial community}

Grazing changes microbial community structures and environmental characteristics. The disrupting effect of grazing on microbial communities may primarily be mediated by aboveground plant and soil geochemical characteristics. Therefore, the present study investigated whether microbial community structure and environmental characteristics were related. RDA revealed that the microbial community structure was formed by primary environmental characteristics,

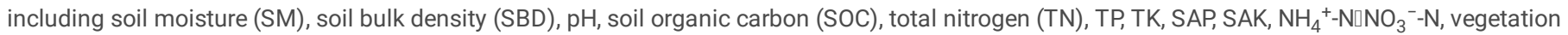
belowground biomass (BGB), litter, and coverage. After removal of the redundant variables, 14 environmental characteristics were chosen for RDA. As shown in Fig. 7A and B, BGB $(p=0.001)$ significantly affected the bacterial community structure, and $p H(p=0.032)$ TN $(p=0.011)$ and litter $(p=0.007)$ significantly affected the fungal community structure. The first two axes of the RDA of the bacterial community (Fig. 9A) accounted for $71.56 \%$ of the total variation in bacterial community composition, and the first axis accounted for $60.33 \%$ of the variation. The $\mathrm{G} 0.23$ samples distributed together, but the sample distribution patterns of other grazing intensities were discrete. The first two axes of the RDA of the fungal community (Fig. 9B) accounted for 25.96\% of the total variation in fungal community composition, and the first axis accounted for $22.73 \%$ of the variation. The G0.00 and G0.92 samples distributed together, but the sample distribution patterns of the other grazing intensities were discrete.

Variance partition analysis was performed to dissect the contributions of soil and plant characteristics to the microbial community structure. These selected characteristics together explained 46.98 and $61.77 \%$ of bacterial and fungal community changes, respectively (Fig. 9 C,D). The contribution of soil and plant characteristics explained 45.35 and $0.75 \%$, respectively, of bacterial community changes and 55.26 and $4.69 \%$, respectively, of the fungal community changes. The combined contribution of soil and plant characteristics explained 0.88 and $1.82 \%$ of the bacterial and fungal community changes, respectively, which reveals a very close interaction between soil and plant characteristics.

\section{Discussion}

Vegetation, soil and microorganisms do not change in isolation, but form a feedback mechanism and interact with each other. Grazing livestock changes the growth of community plants, and soil trampling and excretion affect the nutrient cycle of the soil. Changes in plant growth patterns and the soil environment indirectly affect the microbial environment in the soil, which leads to changes in the microbial community. Soil provides a living environment for microbial communities, and soil characteristics affect microbial communities[31] .

Soil water has a significant inhibitory effect on bacteria, and limits the nutrient uptake and production of bacteria, which leads to metabolism restriction due to nutrient deficiency[32]. Soil pH does not direct impact the microbial community, but it indirectly affects the aboveground vegetation, changes the community characteristics of the aboveground vegetation, and reduces soil microbial energy and organic matter content, which affects the microbial community[33].

\section{Effects of grazing intensity on soil microbial community structure}

The present study examined 18 sample plots of grassland with six grazing intensities in the Hulun Buir grassland to analyse the relationships between soil bacterial and fungal communities and grazing intensity, and the interaction between plant communities and soil physical and chemical properties resulting from grazing intensity and bacterial and fungal communities. The predominant flora in the bacterial communities of Hulun Buir grassland soil was generally consistent between the six grazing regimens, but there were differences in relative abundance, and each region had its own unique fungal populations. Bacterial and fungal diversity was highest in G0.23 and G0.00, respectively. Similarly, Lienhard et al. (2013) [34] found that maximum bacterial and fungal diversity occurred with different utilization schemes. Microbial biomass or diversity increases, decreases, or remains the same depending on the type of grassland, geographical location, and the grazing system and intensity [9-10, 13, 35-39].

Although the diversity of bacterial and fungal communities respond to grazing intensity in different ways, our study showed that the soil microbial community structure changed significantly along a gradient of grazing intensity, which was consistent with changes in soil and plant characteristics.

\section{Relationship between microbial community and environment}

We found that the environmental changes that occurred with changes in grazing intensity contributed differently to different microbial groups in the community (Fig. 9A,B). The results showed a significant correlation between changes in the bacterial community and the underground biomass of the community $(P<0.05)$, but this correlation was not found in the fungal community. There was a significant relationship between litter and the fungal community $(P<0.05)$, but no significant relationship with bacteria was observed. Zhou et al. [13] found that livestock feeding affected aboveground vegetation biomass and community structure, and indirectly changed soil physical and chemical properties. These changes were a result of the interaction of microorganisms with plants [40]. The fungal community structure in our study area was not as sensitive as the bacterial community structure to vegetation biomass changes. This difference may be because fungi are more likely to degrade lignocellulose from different plants than bacteria, which allows them to first obtain resources from many of the relevant available substances [41].

We also found significant direct relationships of bacterial and fungal community structures with soil total nitrogen. Soil nitrogen storage decreases with increasing grazing intensity[42-43]. Nitrogen is one of the most important nutrients for life. Therefore, plant and microbial activities may gradually reduce the content of nitrogen in soil [7]. However, correlations between microbial communities and environmental factors must be carefully explained because it is often very difficult to firmly establish the relationship between microbial communities and soil nutrient cycling [44]. 
We found that the soil characteristic factors evaluated explained over $45 \%$ of the shift in the microbial communities in this study, which suggests that soil characteristics factors are the primary factors influencing microbial community structure. However, $40-55 \%$ of the factors influencing the dynamic changes in the microbial community could not be determined. Multiple studies showed that the effect of mild or moderate grazing on grassland soil was relatively small, and these grazing intensities are beneficial to dry matter production, nutrient cycling, and carbon and nitrogen storage[45-46].

Grazing in $\mathrm{G} 0.23$ had relatively little effect on grassland soil and plant characteristics in the present study. For the bacterial communities, 0.23 Cow.Au ha ${ }^{-1}$

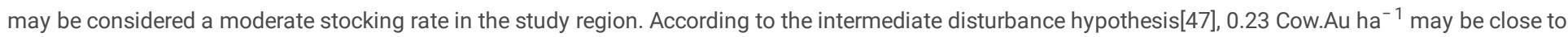
the moderate-disturbance stocking rate in the Hulunbuir meadow grassland.

\section{Conclusion}

The present study examined the soil microbial structure and its relationship with the environment in 6 leymus chinensis meadow steppes with different grazing intensities. High-throughput sequencing results revealed that bacterial and fungal communities were extremely sensitive to grazing and varied with grazing intensity. The diversity of soil bacteria in the light grazing test area was higher than the heavy grazing area, and the diversity of fungi in the nongrazing area was higher than the specific grazing area. Heavy grazing-induced reduction the diversity of soil bacteria and fungi. The underground biomass of the community significantly influenced the bacterial community structure, and $\mathrm{pH}$, total nitrogen and litter significantly influenced the fungal community. In conclusion, heavy grazing reduces the diversity of the community and is not conducive to the development of Hulunbuir meadow grassland.

\section{Abbreviations}

$\mathrm{SM}$, soil moisture;

SBD, soil bulk density;

SOC, soil organic carbon;

TN, total nitrogen;

TP, total phosphorus;

TK, total potassium;

SAP, soil available phosphorus;

SAK, soil available potassium;

$\mathrm{NH}_{4}{ }^{+}-\mathrm{N}$, Soil ammonium nitrogen;

$\mathrm{NO}_{3}{ }^{-} \mathrm{N}$, Soil nitrate nitrogen;

BGB, Belowground biomass.

\section{Declarations}

\section{Ethics approval and consent to participate}

Not applicable

\section{Consent for publicaation}

Not applicable

\section{Availability of data and materials}

The authors declare that the data supporting the findings of this study are available within the paper and its supplementary information files. The sequencing data in this article is available at the NCBI Sequence Read Archive under the accession numbers SUB8689126.

\section{Competinginterests}

The authors declare that they have no competing interests.

FundingThis work was supported by the Fundamental Research Funds for Central Non-profit Scientific Institution (1610132018009), the National Natural Science Foundation of China (31971769), the National Key Research and Development Program of China (2016YFC0500601, 2017YFE0104500), Special Funding for Modern Agricultural Technology Systems from the Chinese Ministry of Agriculture (CARS-34) and Hulunbuir Science and Technology Project (YYYFHZ201903), and Key Laboratory of Grassland Agro-Ecosystems (Lanzhou University, Grant Number:SKLGAE-2019-07区

\section{Authors' Contributions}


YZ participated in the design of the study ideas,carried out the diversity of soil microbial communities, performed the statistical analysis and drafted the manuscript. XPX participated in the analyzed the data. RQL participated in the design of the study ideas. WBX participated in the design of the study ideas. RFZ participated in the analyzed the data. LHL participated in the analyzed the data. XW participated in the analyzed the data. JQC participated in the analyzed the data.RY conceived of the study, and participated in its design and coordination and helped to draft the manuscript.

\section{Acknowledgments}

The authors thank the staff at the HGERS of the CAAS for managing the field experiments and helping with the collection of soil samples.

\section{Authors' Informarion}

${ }^{1}$ Institute of Agricultural Resources and Regional Planning, Chinese Academy of Agricultural Sciences, No 12, Zhonguancun South Street, Haidian District, Beijing 100081, China

2 Environmental Online Monitoring Center of Inner Mongolia, No 39 Tengfei Road, Saihan District, Hohhot, 010011, China

${ }^{3}$ Nanjing Agricultural University, Nanjing 210095, China

${ }^{4}$ Institute of Botany, the Chinese Academy of Sciences, No.20 Nanxincun, Xiangshan, Beijing 100093, China.

\section{References}

1. Yang Y, Wu L, Lin Q, et al. Responses of the functional structure of soil microbial community to livestock grazing in the Tibetan alpine grassland. Global Change Biol. 2013;19:637-48.

2. Nielsen MN, Winding A. Microorganisms as Indicators of Soil Health. Technical Report No. 388. National Environmental Research Institute, Roskilde. 2002.

3. Bai YF, Li DX, Xu ZX. Growth and reproduction of Stipa Krylovii population on a grazing gradient. Acta Ecol Sin. 1999;19(4):479-9.

4. Branson FA, Miller RF. Effects of increased precipitation and grazing management on northeastern montana rangelands. J Range Manag. 1982;34(1):310.

5. Sheng HY, Cao GM, Li GR, et al. Effect of grazing disturbance on plant community of alpine meadow dominated by Potentilla froticosa shrub on Qilian Mountain. Ecology Environmental Sciences. 2009;18(01):235-41.

6. Yan RR, Xin XP, Yan YC, et al. Impacts of Differing Grazing Rates on Canopy Structure and Species Composition in Hulunber Meadow Steppe. Rangeland Ecology Management. 2015;68(1):54-64.

7. Hu H, Chen XJ, Hou FJ, et al. Bacterial and Fungal Community Structures in Loess Plateau Grasslands with Different Grazing Intensities. Frontiers in microbiology. 2017;8:606.

8. Na x f. Zheng GQ, Peng L, et al. Changes of microbial diversity in the rhizosphere of Lycium barbarum I. from Ningxia. Chin J Soil Sci. 2016; 53(1):24152.

9. Ford H, Rousk J, Garbutt A, et al. Grazing effects on microbial community composition, growth and nutrient cycling in salt marsh and sand dune grasslands. Biol Fertil Soils. 2013;49(1):89-98. doi:10.1007/s00374-012-0721-2.

10. Qi S, Zheng H, Lin Q, et al. Effects of livestock grazing intensity on soil biota in a semiarid steppe of Inner Mongolia[J]. Plant Soil. 2011;340(1-2):117-26. doi:10.1007/s11104-010-0463-6.

11. Shan GL, Chen G, Ning F, et al. Dynamic changes of soil microbial and enzyme activities in typical grassland during restoration and succession.Grassland journal. 2012; 20(2):292-297.

12. Wakelin SA, Gregg AL, Simpson RJ, et al. Pasture management clearly affects soil microbial community structure and N-cycling bacteria. Pedobiologia. 2009;52(4):237-51.

13. Zhou X, Wang J, Hao Y, Wang Y. Intermediate grazing intensities by sheep increase soil bacterial diversities in an Inner Mongolian steppe. Biol Fert Soils. 2010;46(8):817-24. doi:10.1007/s00374-010-0487-3.

14. Zhang WW, Gan JG, Han ZW, et al. Carbon and Nitrogen content of microbial biomass in artificial grassland under different grazing intensities. Acta Grassland Sinica. 2003;11(4):343-5.

15. Cao CY, Shao JF, Jiang DM, et al. Effects of Fence Enclosure on Soil Nutrients and Biological Activities in Highly Degraded Grasslands. Journal of Northeastern University. 2011;32(3):427-30 + 451.

16. Li XZ, Qu QH. Soil microbial biomass carbon and nitrogen characteristics in grassland of the Mongolian Plateau. Acta Sodiae. 2002;39(1):97-104.

17. Gou YN, Nan ZB. Effects of grazing on soil microorganisms in grassland. Acta ecologica sinica. 2015;24(10):194-205.

18. Zhalnina K, Dias R, Quadros PDD, et al. Soil pH Determines Microbial Diversity and Composition in the Park Grass Experiment. Microb Ecol. 2015;69(2):395-406.

19. Sun YF, Shen JP, Zhang CJ, et al. Changes of soil ammonia oxidation and denitrifying microorganisms under different grazing intensities. Acta Ecol Sin. 2018;38(8):1-10.

20. Xun WB, Yan RR, Rrn Y, et al. Grazing-induced microbiome alterations drive soil organic carbon turnover and productivity in meadow steppe. Microbiome. $2018 ; 6(1)$. 
21. Hu YF, Peng JJ, Yuan S, et al. Influence of ecological restoration on vegetation and soil microbiological properties in Alpine-cold semi-humid desertified land. Ecological Engineering. 2016;94(1):88-94.

22. Yao ML, Qiao YL, Shi PW, et al. Soil bacterial community responses to warming and grazing in a Tibetan alpine meadow. Fems Microbiology Ecology. 2016;92(1):152.

23. Zhang Y, Dong S, Gao Q, et al. Soil bacterial and fungal diversity differently correlated with soil biochemistry in alpine grassland ecosystems in response to environmental changes. Sci Rep. 2017;7:43077.

24. Zhao Q, Niu H, Wang Y, et al. Response of soil bacterial communities to moisture and grazing in the Tibetan alpine steppes on a small spatial scale. Geomicrobiology. 2019; 1-11.

25. Regan KM, Nunan N, Boeddinghaus RS, et al. Seasonal controls on grassland microbial biogeography: are they governed by plants, abiotic properties or both. Soil Biol Biochem. 2014;71:21-30.

26. Wang KH, Mcsorley R, Bohlen P, et al. Cattle grazing increases microbial biomass and alters soil nematode communities in subtropical pastures. Soil Biol Biochem. 2006;38(7):1956-65. doi:10.1016/j.soilbio.2005.12.019.

27. Huws SA, Edwards JE, Kim EJ, et al. Specificity and sensitivity of eubacterial primers utilized for molecular profiling of bacteria within complex microbial ecosystems. J Microbiol Methods. 2007;70:565-9. doi:10.1016/j.mimet.2007.06.013.

28. Rousk J, Baath E, Brookes PC, et al. Soil bacteria and fungal communities across a pH gradient in an arable soil. ISME J. 2010;4:1340-51. doi:10.1038/ismej.2010.58.

29. Segata N, Izard J, Waldron L, et al. Metagenomic biomarker discovery and explanation. Genome Biol. 2011;12:60. doi:10.1186/gb-2011-12-6-r60.

30. Qu WH, Li ZG, Li J. Short-term effects of single and combined application of organic materials on microbial community functional diversity in desertified soil. Chinese Soil Fertilizer. 2017;1(4):78-85.

31. Yang Y, Jia LX, Qiao JR, et al. Effects of heavy grazing on soil nutrient and microbial diversity in desert steppe. Acta Grassland Sinica. 2019;41(04):72-9.

32. Birgander J, Rousk J, Olsson PA. Comparison of fertility and seasonal effects on grassland microbial com munities. Soil Biol Biochem. 2014;76(1):80-9.

33. Joshua S, Balser TC, Matthew W. Microbial stress response physiology and its implications for ecosystem function. Ecology. 2007;88(6):1386-94.

34. Lienhard $P$, Tivet $F$, Chabanne A, et al. No-till and cover crops shift soil microbial abundance and diversity in Laos tropical grassland. Agron Sustain Dev. 2013;33:375-84. doi:10.1007/s13593-012-0099-4.

35. Ruess RW, Mc Naughton SJ. Grazing and the dynamics of nutrient and energy regulated microbial processes in the Serengeti grasslands. Oikos. 1987;49:101-10. doi:10.2307/3565559.

36. Bardgett RD, Leemans DK, Cook R, et al. Seasonality of soil biota of grazed and ungrazed hill grasslands. Soil Biol Biochem. 1997;29:1285-94. doi:10.1016/S0038-0717(97)00019-9.

37. Jangid K, Williams MA, Franzluebbers AJ, et al. Relative impacts of land-use, management intensity and fertilization upon soil microbial community structure in agricultural systems. Soil Biol Biochem. 2008;40:2843-53. doi:10.1016/j.soilbio.2008.07.030.

38. Death RG, Barquín J. Geographic location alters the diversity-disturbance response. Freshw Sci. 2012;31:636-46. doi:10.1899/11-059.1.

39. Gou YN, Nan ZB, Hou FJ. Diversity and structure of a bacterial community in grassland soils disturbed by sheep grazing, in the Loess Plateau of northwestern China. Genet Mol Res. 2015;14:16987-99. doi: 10.4238/2015. December.15.5.

40. Ortiz-Castro R, Contreras-Cornejo HA, Macias-Rodriguez L, et al. The role of microbial signals in plant growth and development. Plant Signal Behav. 2009;4:701-12. doi:10.4161/psb.4.8.9047.

41. Chapin FS III, Matson PA, Vitousek P. Principles of Terrestrial Ecosystem Ecology, 2nd Edn. New York, NY: Springer-Verlag.2011. doi: 10.1007/978-1-44199504-9.

42. Cui XY, Wang YF, Niu HS, et al. Effect of long-term grazing on soil organic carbon content in semiarid steppes in Inner Mongolia. Ecol Res. 2005;20:51927. doi:10.1007/s11284-005-0063-8.

43. He NP, Yu Q, Wu L, et al. Carbon and nitrogen store and storage potential as affected by land-use in a Leymus chinensis grassland of northern China. Soil Biol Biochem. 2008; 40: 2952-9. doi: 10.1016/j.s oilbio.2008.08.018.

44. Bardgett RD. The Biology of Soil, a Community and Ecosystem Approach. New York: Oxford University Press; 2005. doi:10.1093/acprof:oso/9780198525035.001.0001.

45. Li CL, Hao XY, Zhao ML, et al. Influence of historic sheep grazing on vegetation and soil properties of a desert steppe in Inner Mongolia. Agric Ecosyst Environ. 2008;128:109-16. doi:10.1016/j.agee.2008. 05.008.

46. Chen YP, Li YQ, Zhao XY, et al. Light fraction and total organic carbon and nitrogen stores in desertified sandy grassland soil as affected by grazing and livestock exclusion. J Soil Water Conserv. 2010;24:182-6.

47. Connell JH. Diversity of tropical rainforests and coral reefs. Science. 1978; 199: 1304-10. doi: 10.1126/ science.199.4335.1302.

\section{Tables}

\section{Table 1}

Changes of Plant characteristics and soil physical and chemical properties under different grazing intensities in the growing seasons of 2018 ( $\mathrm{M} \pm \mathrm{s}$.e.). Abbreviations:SM, soil moisture; SBD, soil bulk density; SOC, soil organic carbon; TN, total nitrogen; TP,total phosphorus; TK,total potassium; SAP, soil available phosphorus; SAK, soil available potassium; $\mathrm{NH}_{4}{ }^{+}-\mathrm{N}$, Soil ammonium nitrogen; $\mathrm{NO}_{3}{ }^{-} \mathrm{N}$, Soil nitrate nitrogen; $\mathrm{BGB}$, Belowground biomass. 


\begin{tabular}{|c|c|c|c|c|c|c|c|}
\hline & factors & $\mathrm{G} 0.00$ & $\mathrm{G} 0.23$ & G0.34 & $\mathrm{G} 0.46$ & G0.69 & G0.92 \\
\hline \multirow{11}{*}{$\begin{array}{l}\text { soil } \\
\text { characteristics }\end{array}$} & $\mathrm{SM}(\%)$ & $20.81 \pm 1.00 a$ & $20.34 \pm 0.57 a b$ & $19.53 \pm 0.65 a b$ & $18.47 \pm 0.90 \mathrm{bc}$ & $18.01 \pm 0.19 c$ & $17.94 \pm 0.59 c$ \\
\hline & $\operatorname{SBD}\left(\mathrm{g} / \mathrm{cm}^{3}\right)$ & $0.96 \pm 0.02 \mathrm{a}$ & $0.99 \pm 0.03 a$ & $1.01 \pm 0.01 \mathrm{a}$ & $1.02 \pm 0.04 a$ & $1.03 \pm 0.01 a$ & $1.05 \pm 0.04 a$ \\
\hline & $\mathrm{pH}$ & $6.94 \pm 0.45 a$ & $6.59 \pm 0.16 a$ & $6.59 \pm 0.12 a$ & $6.89 \pm 0.10 \mathrm{a}$ & $6.47 \pm 0.09 a$ & $6.59 \pm 0.05 a$ \\
\hline & $\mathrm{SOC}(\mathrm{g} / \mathrm{kg})$ & $39.23 \pm 0.07 a$ & $41.26 \pm 1.14 \mathrm{a}$ & $42.72 \pm 2.52 a$ & $44.07 \pm 3.15 a$ & $43.78 \pm 4.63 a$ & $38.32 \pm 1.80 \mathrm{a}$ \\
\hline & $\mathrm{TN}(\mathrm{g} / \mathrm{kg})$ & $3.37 \pm 0.11 \mathrm{ab}$ & $3.39 \pm 0.08 a b$ & $3.34 \pm 0.09 a b$ & $3.41 \pm 0.03 a$ & $3.18 \pm 0.04 a b$ & $3.13 \pm 0.09 b$ \\
\hline & $\mathrm{TP}(\mathrm{g} / \mathrm{kg})$ & $0.43 \pm 0.03 a$ & $0.38 \pm 0.01 a$ & $0.44 \pm 0.00 \mathrm{a}$ & $0.41 \pm 0.04 a$ & $0.48 \pm 0.05 a$ & $0.46 \pm 0.08 a$ \\
\hline & $\mathrm{TK}(\mathrm{g} / \mathrm{kg})$ & $15.85 \pm 0.45 b$ & $17.28 \pm 0.44 a b$ & $17.62 \pm 0.28 a$ & $18.84 \pm 0.59 a$ & $18.93 \pm 0.89 a$ & $18.69 \pm 0.42 a$ \\
\hline & $\mathrm{SAP}(\mathrm{mg} / \mathrm{kg})$ & $3.73 \pm 0.17 a$ & $3.80 \pm 0.17 a$ & $3.74 \pm 0.55 a$ & $3.70 \pm 0.73 a$ & $3.46 \pm 0.28 a$ & $3.24 \pm 0.12 a$ \\
\hline & $\mathrm{SAK}(\mathrm{mg} / \mathrm{kg})$ & $309.80 \pm 77.40 a$ & $314.44 \pm 12.46 a$ & $279.32 \pm 35.12 a$ & $354.71 \pm 73.45 a$ & $307.49 \pm 56.78 a$ & $330.37 \pm 25.75 a$ \\
\hline & $\begin{array}{l}\mathrm{NH}_{4}{ }^{+}-\mathrm{N} \\
\nabla \mathrm{mg} / \mathrm{kg})\end{array}$ & $5.72 \pm 0.95 a$ & $5.38 \pm 0.66 a$ & $6.22 \pm 1.17 a$ & $5.85 \pm 1.48 a$ & $4.66 \pm 1.08 a$ & $3.22 \pm 0.00 \mathrm{a}$ \\
\hline & $\begin{array}{l}\mathrm{NO}_{3}^{-}-\mathrm{N} \\
\nabla \mathrm{mg} / \mathrm{kg})\end{array}$ & $20.09 \pm 3.21 b$ & $16.08 \pm 1.20 b$ & $18.91 \pm 2.28 b$ & $17.94 \pm 2.39 b$ & $34.97 \pm 8.63 a$ & $21.31 \pm 1.47 b$ \\
\hline \multirow[t]{3}{*}{$\begin{array}{l}\text { Vegetation } \\
\text { characteristics }\end{array}$} & $\mathrm{BGB}\left(\mathrm{g} / \mathrm{m}^{2}\right)$ & $1,162.38 \pm 145.85 a$ & $972.48 \pm 69.38 a b$ & $1,011.36 \pm 112.08 a b$ & $605.31 \pm 59.90 c$ & $790.75 \pm 70.41 b c$ & $849.41 \pm 96.75 a b c$ \\
\hline & Litter $\left(\mathrm{g} / \mathrm{m}^{2}\right)$ & $206.28 \pm 27.41 a$ & $135.48 \pm 15.77 b$ & $105.36 \pm 31.84 b$ & $67.02 \pm 27.94 \mathrm{bc}$ & $0.00 \pm 0.00 c$ & $0.00 \pm 0.00 \mathrm{c}$ \\
\hline & Coverage(\%) & $84.65 \pm 0.63 a$ & $80.25 \pm 1.16 a b$ & $80.12 \pm 1.80 \mathrm{ab}$ & $78.01 \pm 1.34 b$ & $78.23 \pm 10.49 b$ & $68.84 \pm 2.87 \mathrm{c}$ \\
\hline
\end{tabular}

\section{Figures}

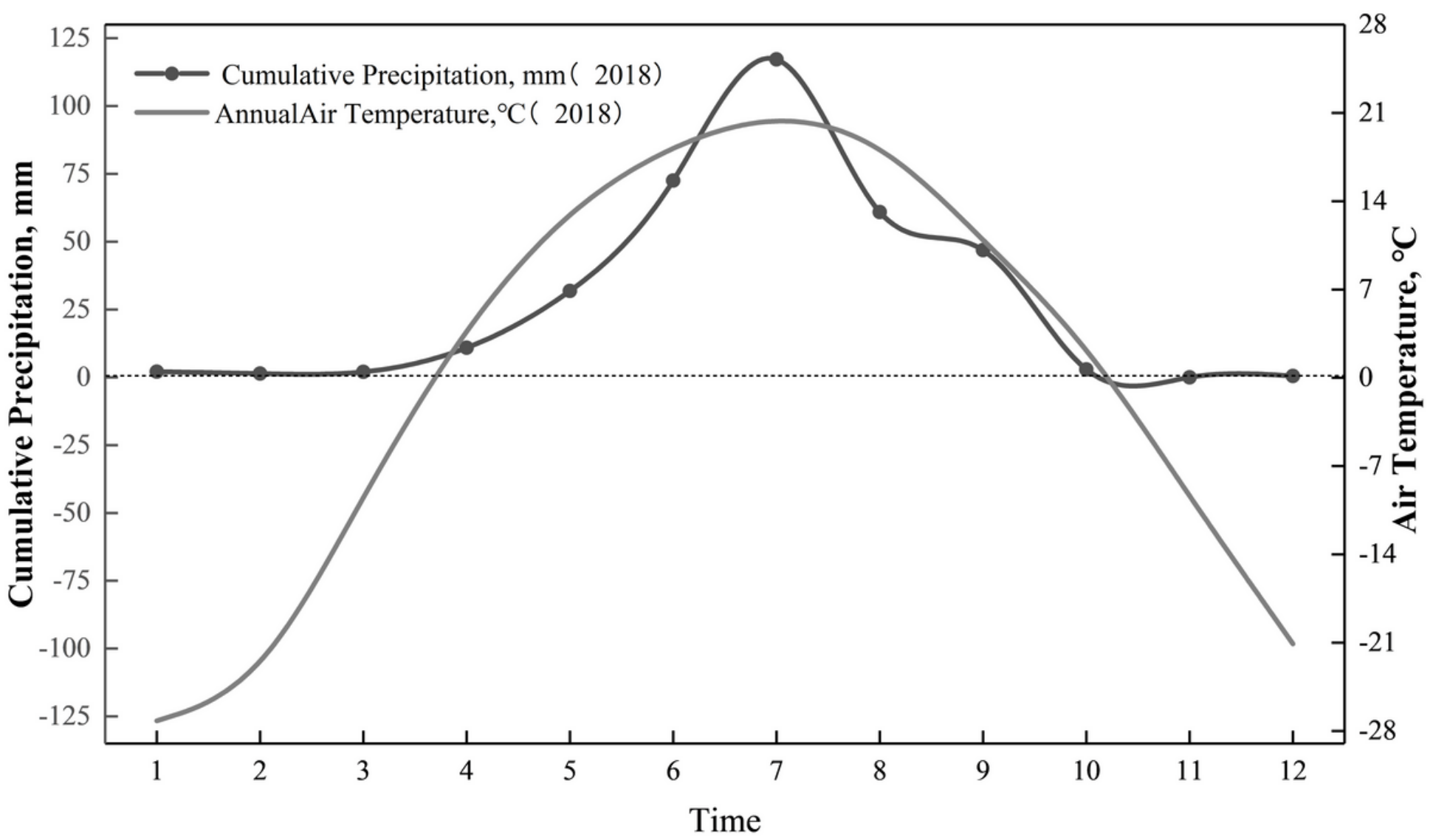

Figure 1

Monthly precipitation and temperature in 2018 for the experiment plot. 

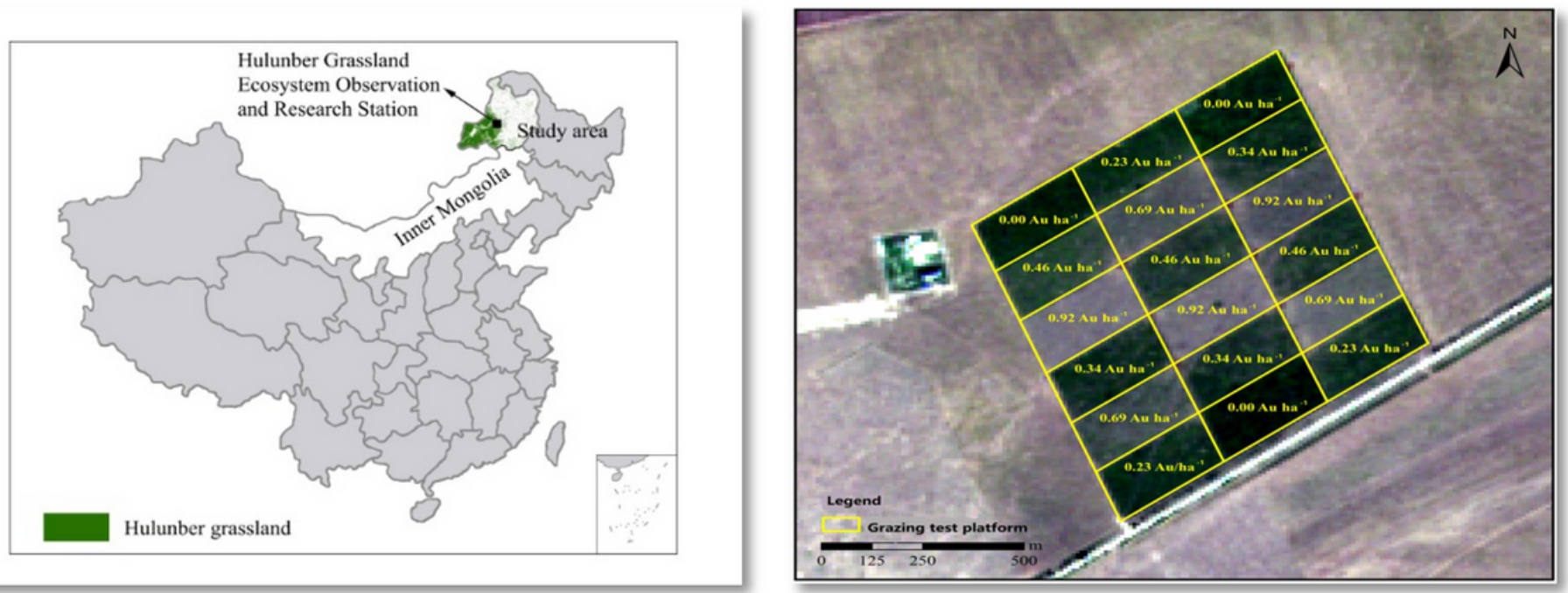

\section{Figure 2}

Geographic location of the study sites and design diagram of different cattle grazing intensities. The values $0.00,0.23,0.34,0.46,0.69$ and 0.92 AU ha- 1 correspond to different livestock rates $(1 \mathrm{AU}=500 \mathrm{~kg}$ of adult cattle). The stocking rates were achieved using $0,2,3,4,6$ and 8 young cattle (250-300 kg) per plot. Note: The designations employed and the presentation of the material on this map do not imply the expression of any opinion whatsoever on the part of Research Square concerning the legal status of any country, territory, city or area or of its authorities, or concerning the delimitation of its frontiers or boundaries. This map has been provided by the authors.
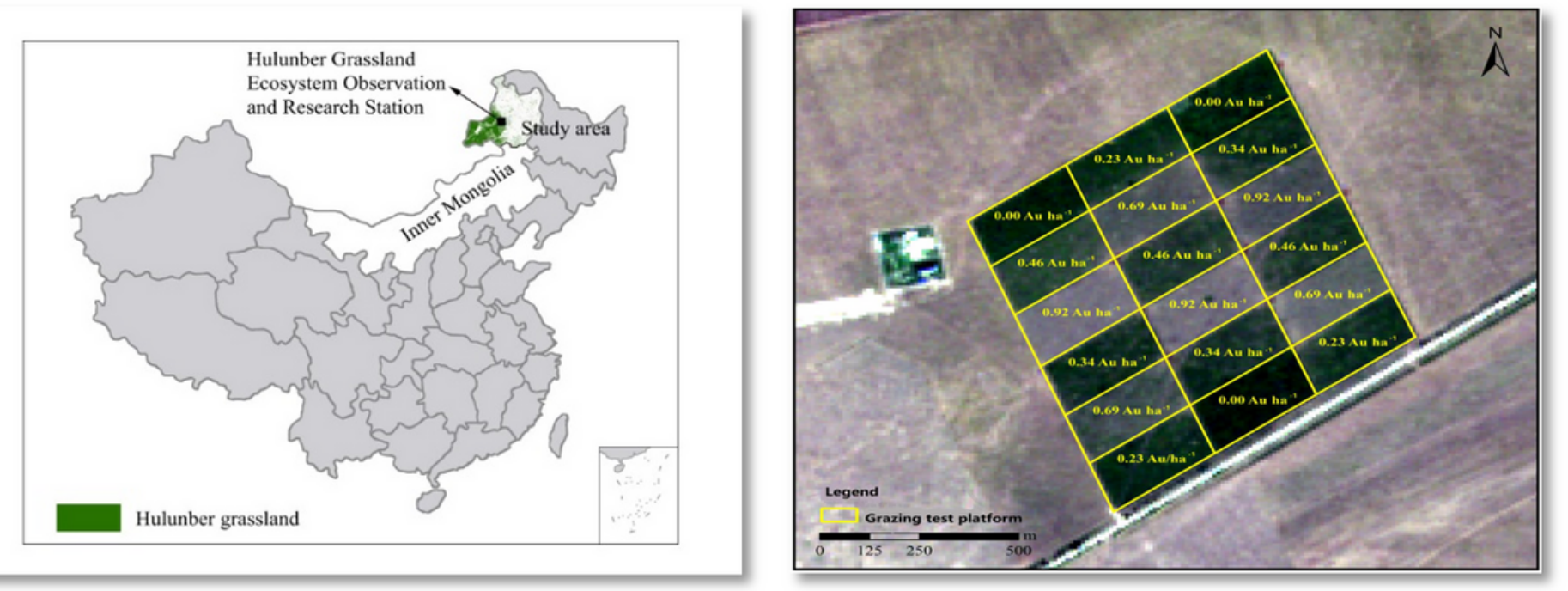

\section{Figure 2}

Geographic location of the study sites and design diagram of different cattle grazing intensities. The values $0.00,0.23,0.34,0.46,0.69$ and 0.92 AU ha- 1 correspond to different livestock rates ( $1 \mathrm{AU}=500 \mathrm{~kg}$ of adult cattle). The stocking rates were achieved using $0,2,3,4,6$ and 8 young cattle (250-300 kg) per plot. Note: The designations employed and the presentation of the material on this map do not imply the expression of any opinion whatsoever on the part of Research Square concerning the legal status of any country, territory, city or area or of its authorities, or concerning the delimitation of its frontiers or boundaries. This map has been provided by the authors. 

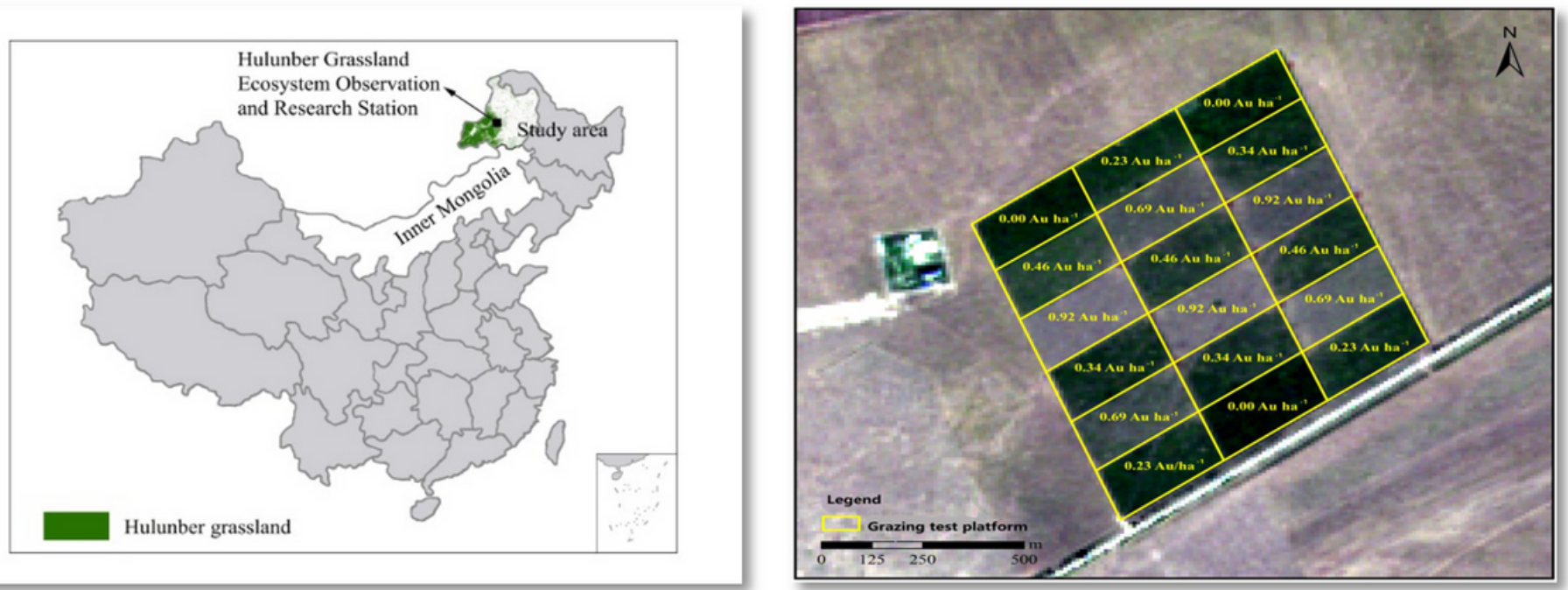

\section{Figure 2}

Geographic location of the study sites and design diagram of different cattle grazing intensities. The values $0.00,0.23,0.34,0.46,0.69$ and 0.92 AU ha- 1 correspond to different livestock rates $(1 \mathrm{AU}=500 \mathrm{~kg}$ of adult cattle). The stocking rates were achieved using $0,2,3,4,6$ and 8 young cattle (250-300 kg) per plot. Note: The designations employed and the presentation of the material on this map do not imply the expression of any opinion whatsoever on the part of Research Square concerning the legal status of any country, territory, city or area or of its authorities, or concerning the delimitation of its frontiers or boundaries. This map has been provided by the authors.
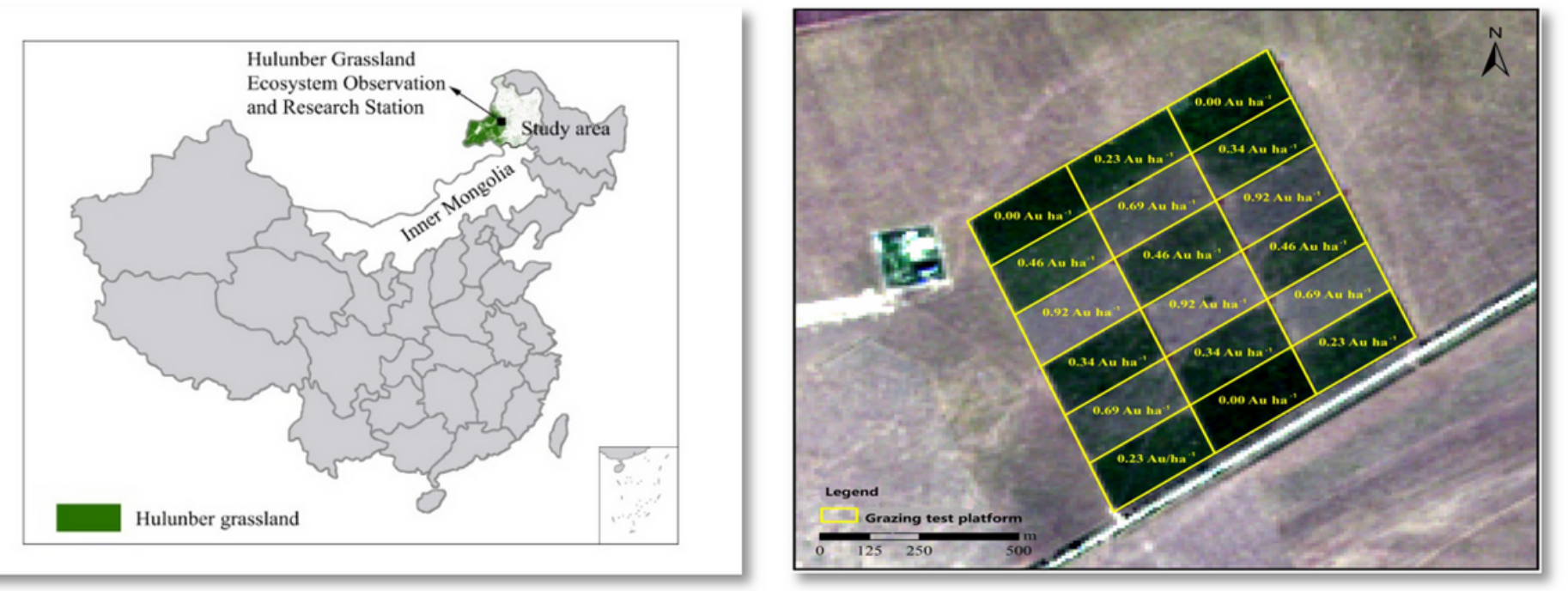

\section{Figure 2}

Geographic location of the study sites and design diagram of different cattle grazing intensities. The values $0.00,0.23,0.34,0.46,0.69$ and 0.92 AU ha- 1 correspond to different livestock rates ( $1 \mathrm{AU}=500 \mathrm{~kg}$ of adult cattle). The stocking rates were achieved using $0,2,3,4,6$ and 8 young cattle (250-300 kg) per plot. Note: The designations employed and the presentation of the material on this map do not imply the expression of any opinion whatsoever on the part of Research Square concerning the legal status of any country, territory, city or area or of its authorities, or concerning the delimitation of its frontiers or boundaries. This map has been provided by the authors. 

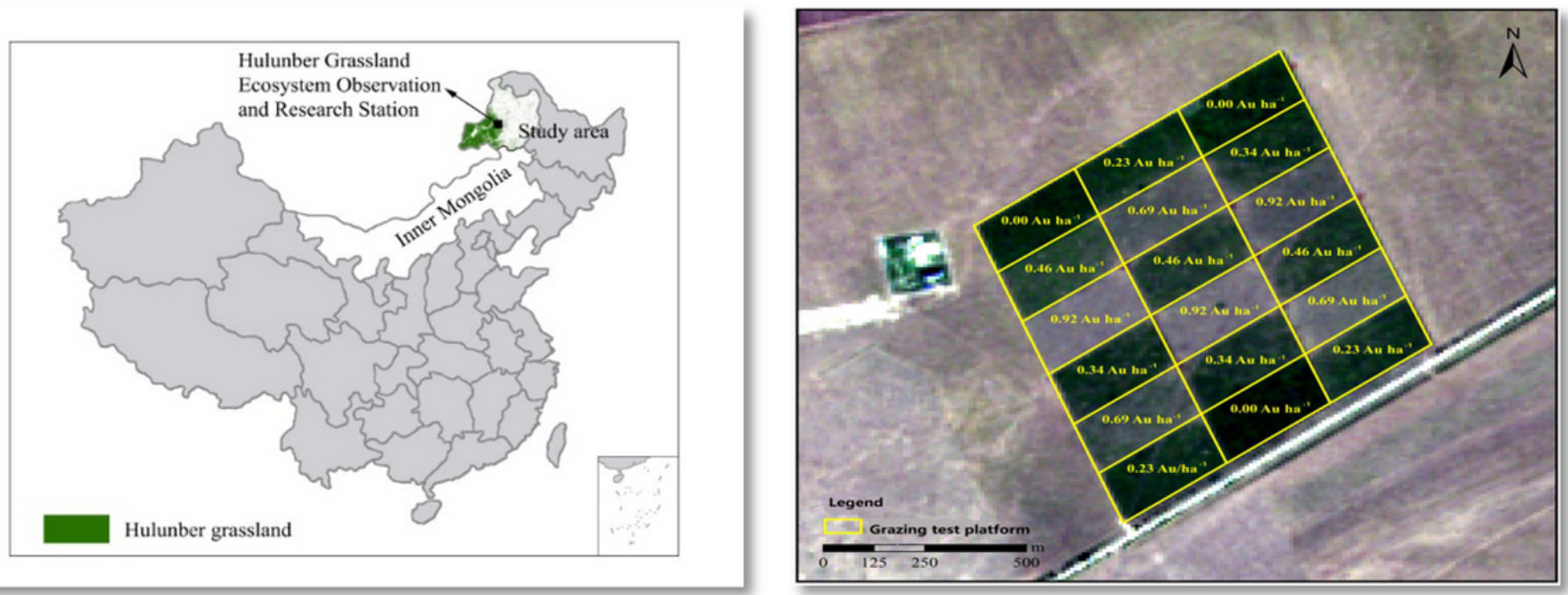

Figure 3

Geographic location of the study sites and design diagram of different cattle grazing intensities. The values $0.00,0.23,0.34,0.46,0.69$ and $0.92 \mathrm{AU}$ ha- 1 correspond to different livestock rates $(1 \mathrm{AU}=500 \mathrm{~kg}$ of adult cattle). The stocking rates were achieved using $0,2,3,4,6$ and 8 young cattle (250-300 kg) per plot. Note: The designations employed and the presentation of the material on this map do not imply the expression of any opinion whatsoever on the part of Research Square concerning the legal status of any country, territory, city or area or of its authorities, or concerning the delimitation of its frontiers or boundaries. This map has been provided by the authors.

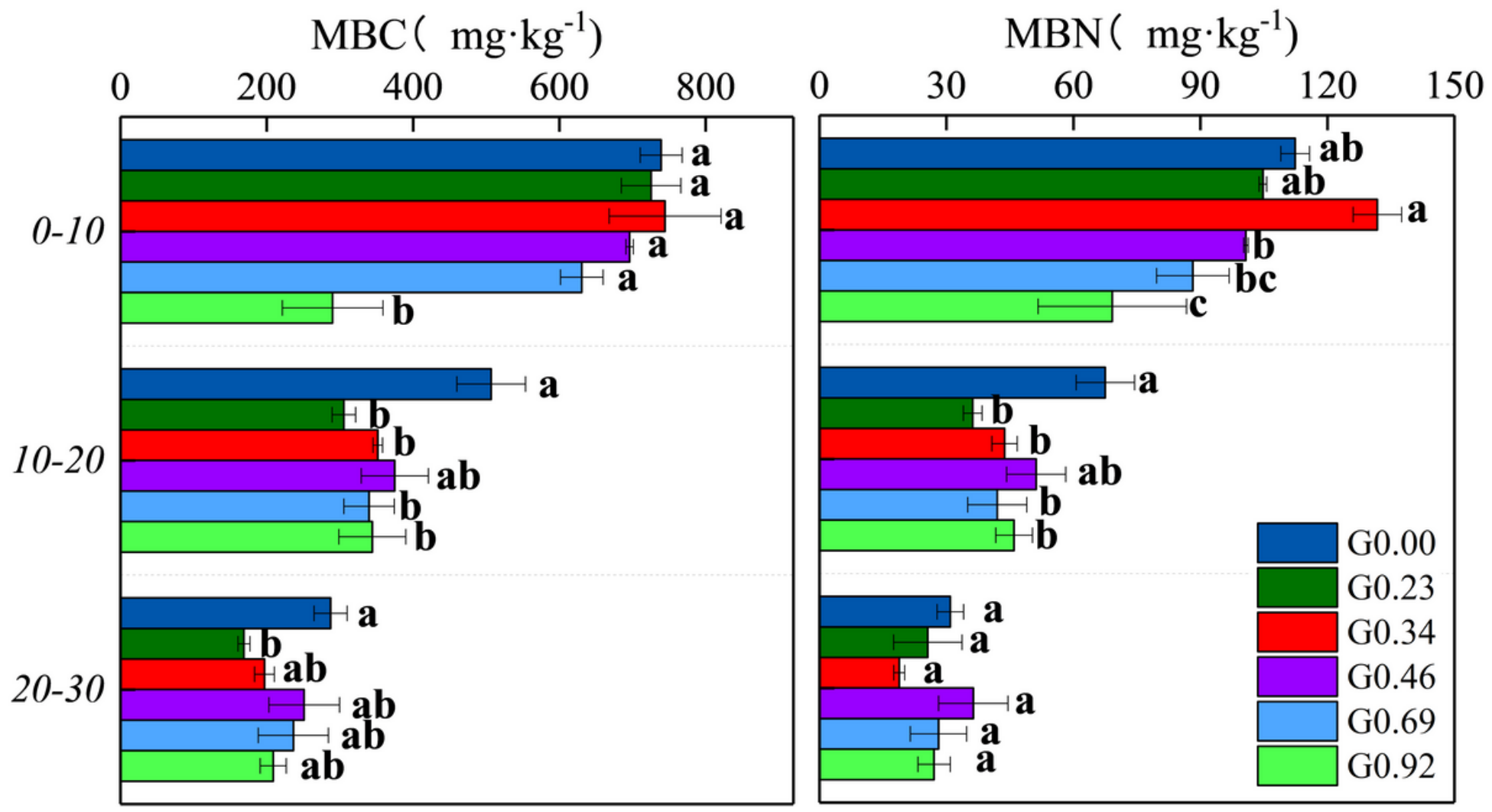

Figure 4

Microbial carbon (MBC) and nitrogen (MBN) contents in August under different grazing intensities. Lower case letters represent significant differences between different grazing intensities $(P<0.05)$. 


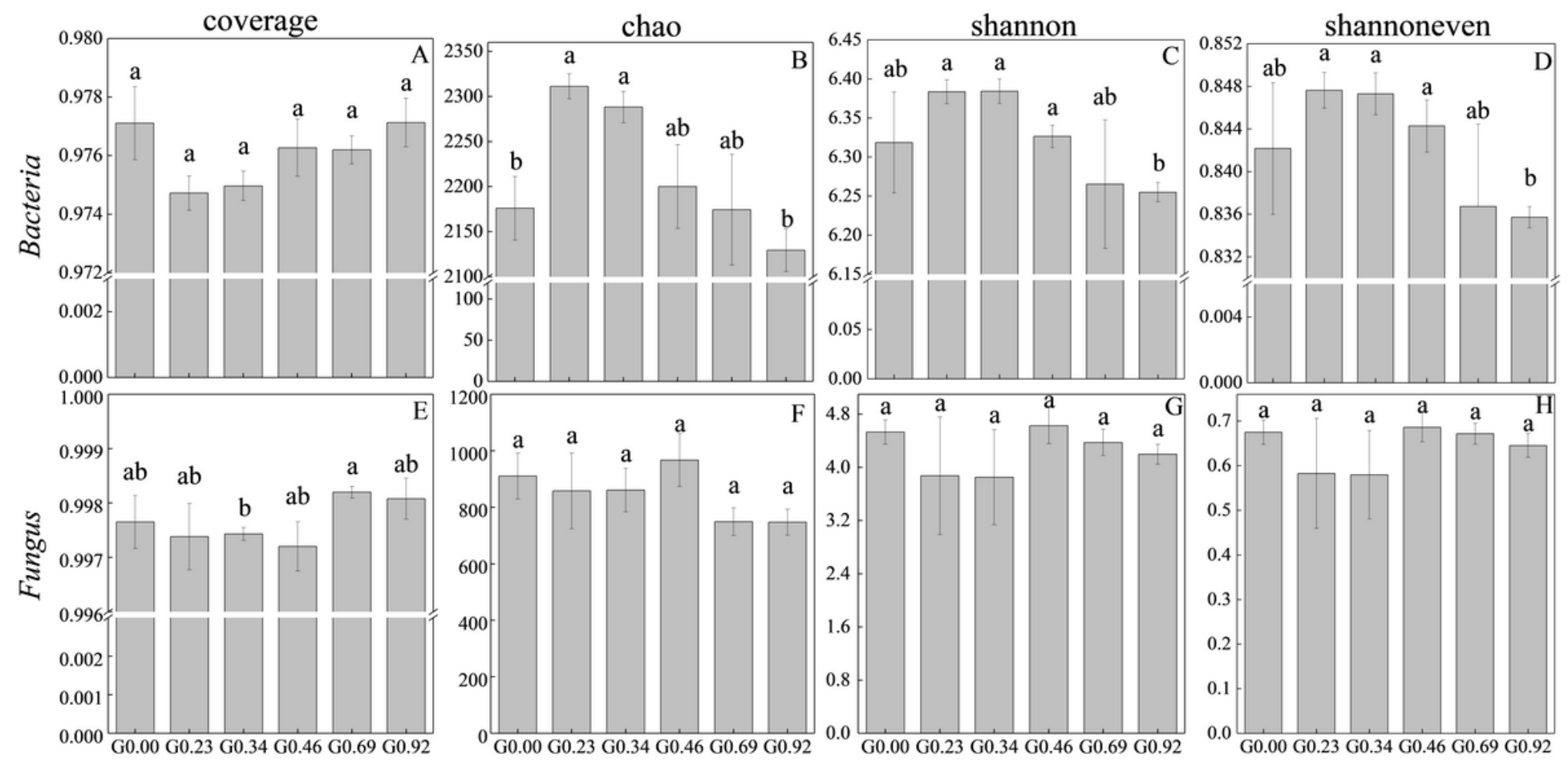

Figure 5

Estimated values of bacterial and fungal community a diversity indexes. Chao reflects the richness of the community. Shannon reflects the diversity of the community and is used to estimate one of the indexes of microbial diversity in the sample. Shannoneven reflects the homogeneity of the community. Significant differences are indicated by different letters. 
Bacteria Community barplot analysis

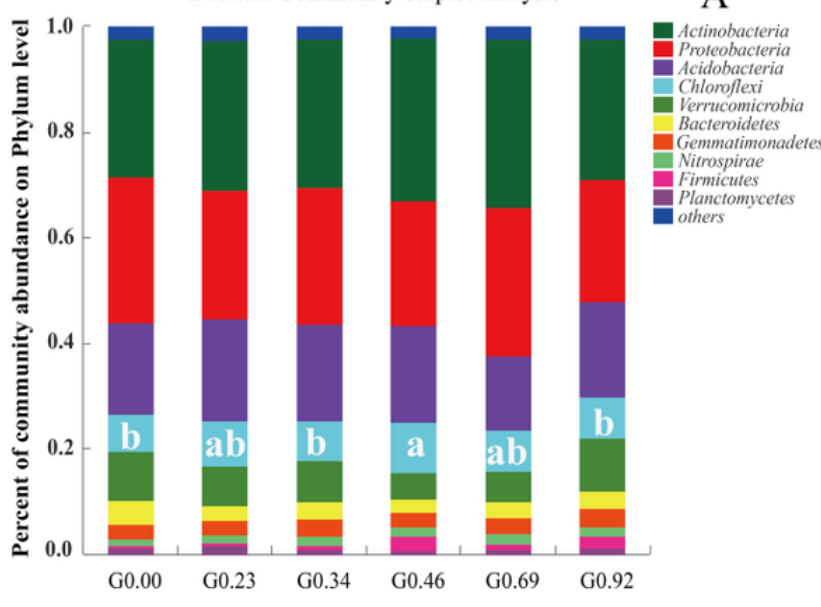

Bacteria Community heatmap
A

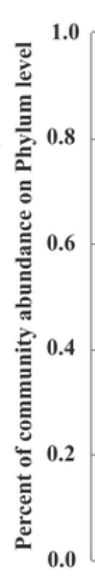

Fungus Community barplot analysis

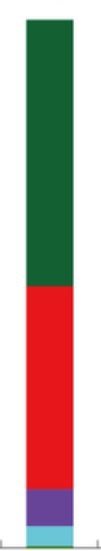

G0.00 G0.23

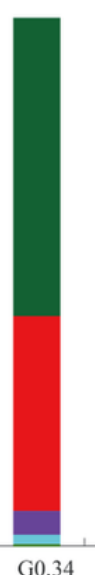

Fungus Community heatmap

\section{B}

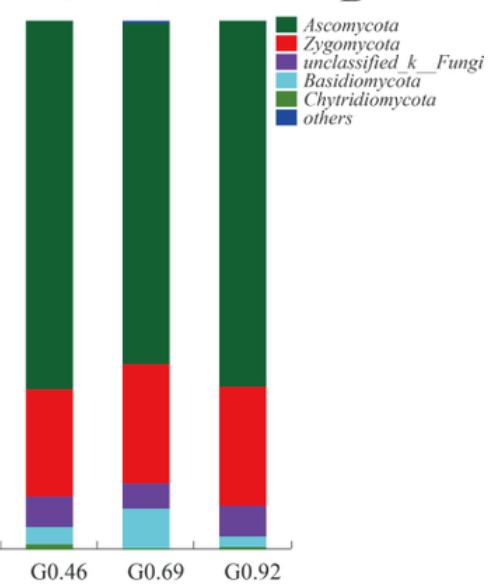

D

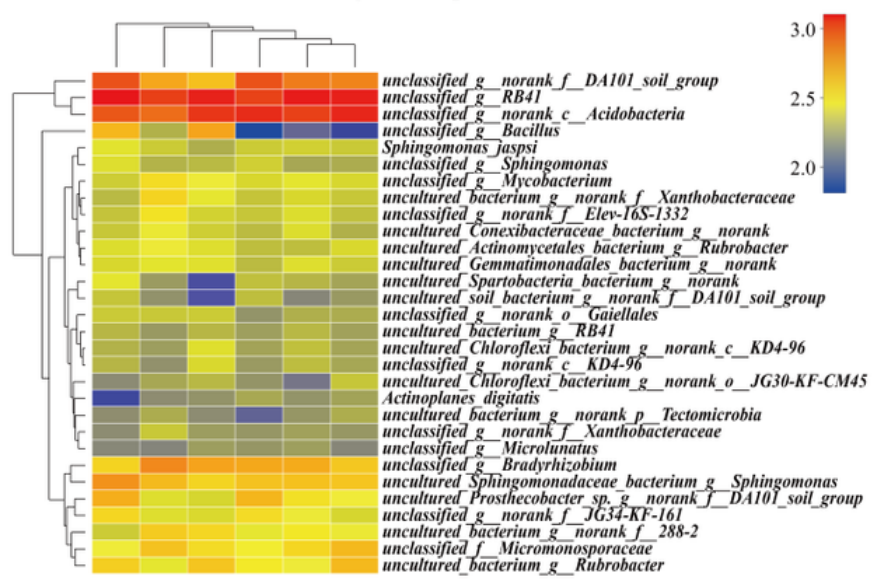

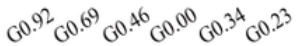

Grazing intensity(Cow.Au.hm-1

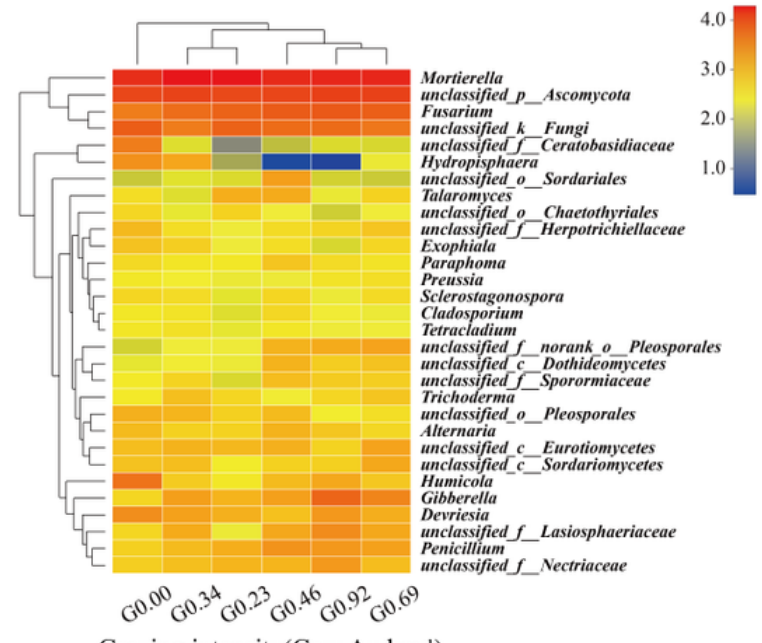

Grazing intensity(Cow.Au.hm"-1)

\section{Figure 6}

According to the rule that the proportion of microbial abundance was greater than $1 \%$, the dominant phylum histograms of soil bacteria (A) and fungi (B) were drawn. The abscissa is the group name, and the ordinate is the proportion of the species in the sample. The columns of different colours represent different species, and the length of the column represents the proportion of the species. Bacterial (C) and fungal (D) community heatmaps. The abscissa/ordinate is the sample name. In figure A and B, the vertical/horizontal coordinates are the proportion of species in this sample. Columns of different colours represent different species, and the length of columns represents the proportion of this species. In $C$ and $D$, the ordinate is the species name, and the variation of abundance of different species in the sample is shown by colour gradient of the colour block. The value represented by the colour gradient is on the right of the figure. Colour gradients are used to represent the size of the data in a two-dimensional matrix or table and to present information about community species composition and species abundance. Clustering was carried out according to the similarity of the abundance between species or samples, and the results are presented in the community heatmap, which groups the species with high and low abundance clusters in blocks, and reflects the similarity and difference of community composition of different groups (or samples) at each taxonomic level through colour change and similarity degree. 

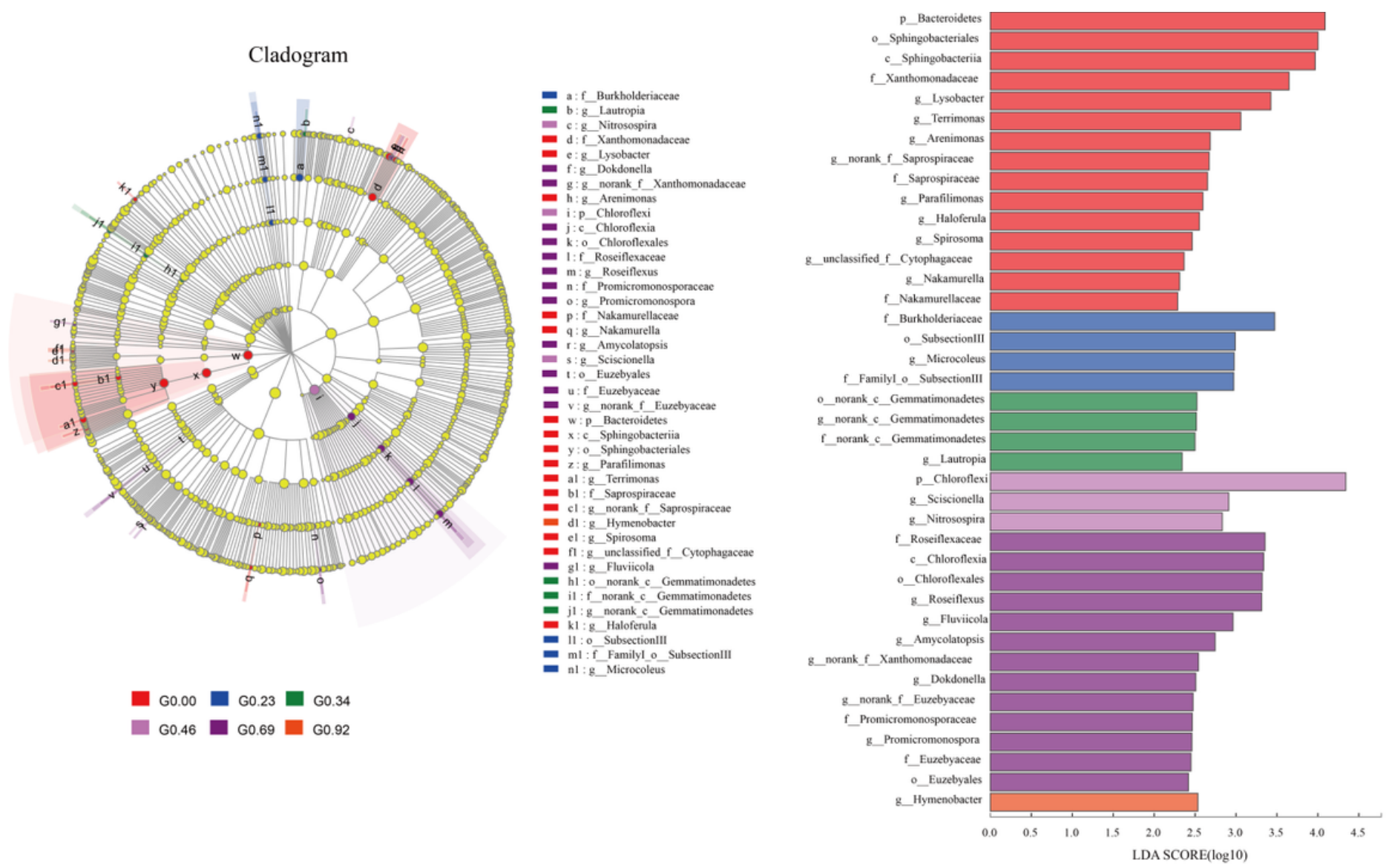

\section{Figure 7}

Cladogram showing the phylogenetic distribution of the bacterial lineages associated with soils with different grazing intensities. Indicator bacteria with LDA scores of 2 or greater in bacterial communities associated with soils with different grazing intensities. Different-coloured regions represent different constituents. Circles indicate phylogenetic levels from domain to genus. The diameter of each circle is proportional to the abundance of the group.
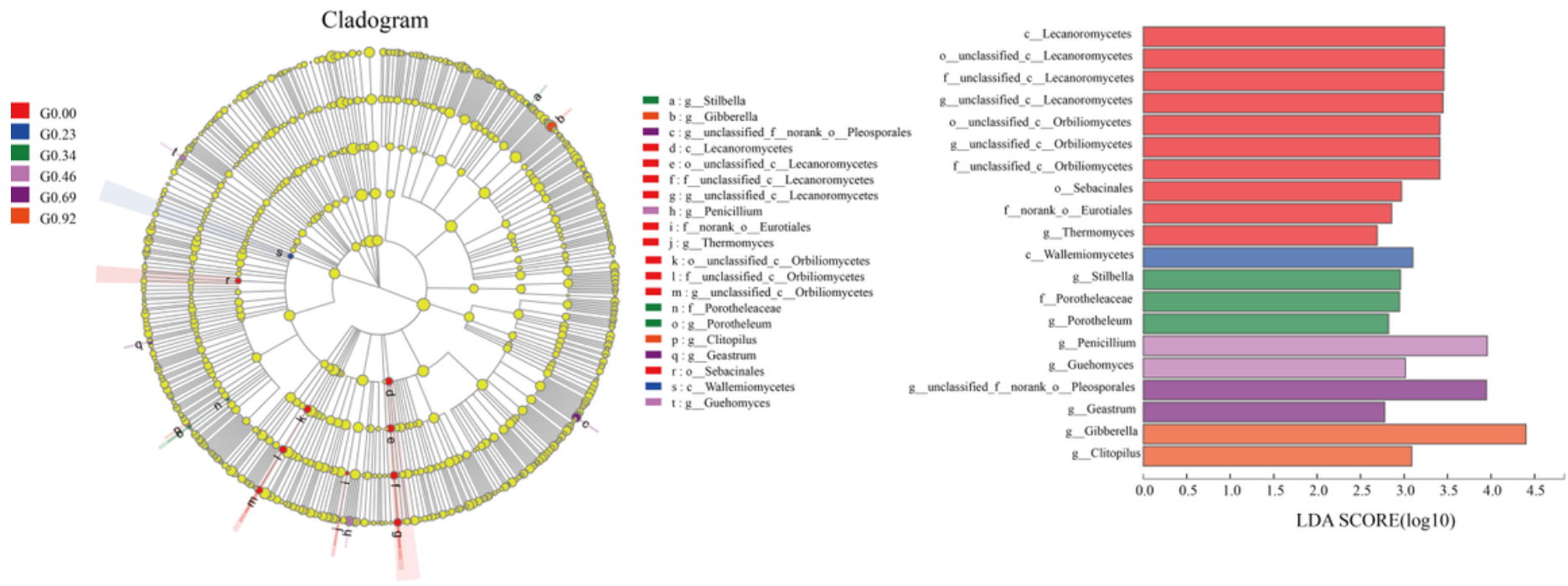

Figure 8

Cladogram showing the phylogenetic distribution of the fungal lineages associated with soils with different grazing intensities. Indicator fungus with LDA scores of 2 or greater in fungal communities associated with soil with different grazing intensities. Different-coloured regions represent different constituents. Circles indicate phylogenetic levels from domain to genus. The diameter of each circle is proportional to the abundance of the group. 


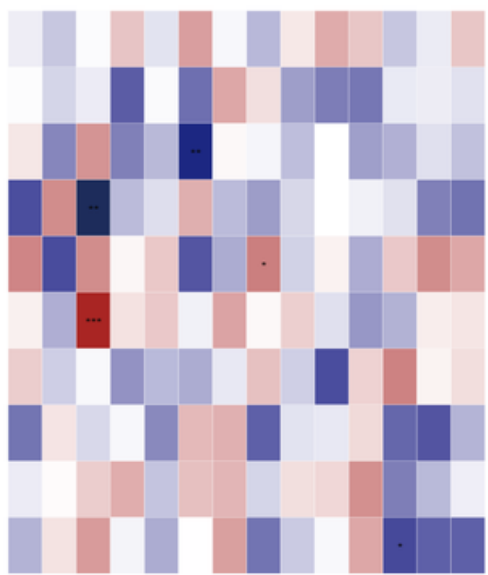

Bradyrhizobium

RB41

Rubrobacter

Sphingomonas

norank_c_Acidobacteria

norank_c_KD4-96

norank_f_DA101_soil_group

norank_f_Elev-16S-1332

norank $\mathrm{f}$ Xanthobacteraceae

norank_o__Gaiellales

की
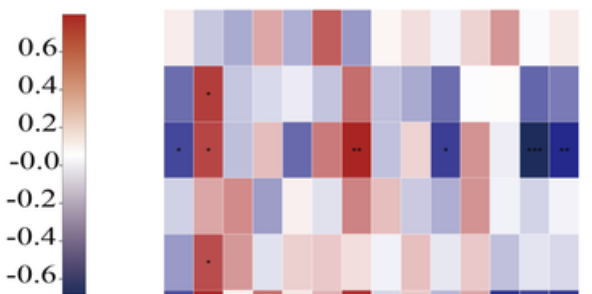

Devriesia

Fusarium

Gibberella

Humicola

Mortierella

Penicillium

unclassified_f__Lasiosphaeriaceae

unclassified_f__Nectriaceae

unclassified_k_Fungi

unclassified_p_Ascomycota

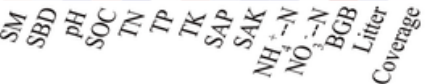

0.6
0.4
0.2
-0.0
-0.2
-0.4
-0.6

Figure 9

Heatmap analyses of the correlations between bacterial and fungal species abundance and environmental factors. By calculating the Spearman correlation coefficient between the environmental factors of the top 10 species and the total abundance, the obtained numerical matrix is visually displayed in the heatmap. The $\mathrm{X}$ axis and the $\mathrm{Y}$ axis are the environmental factors and species, respectively. Colour changes reflect the data information in the twodimensional matrix or table. The colour depth represents the size of the data value, which is directly represented by the defined colour depth. The legend on the right is the colour interval of different $R$ values.* $0.01<P \leq 0.05$, ** $0.001<P \leq 0.01$, *** $P \leq 0.001$.
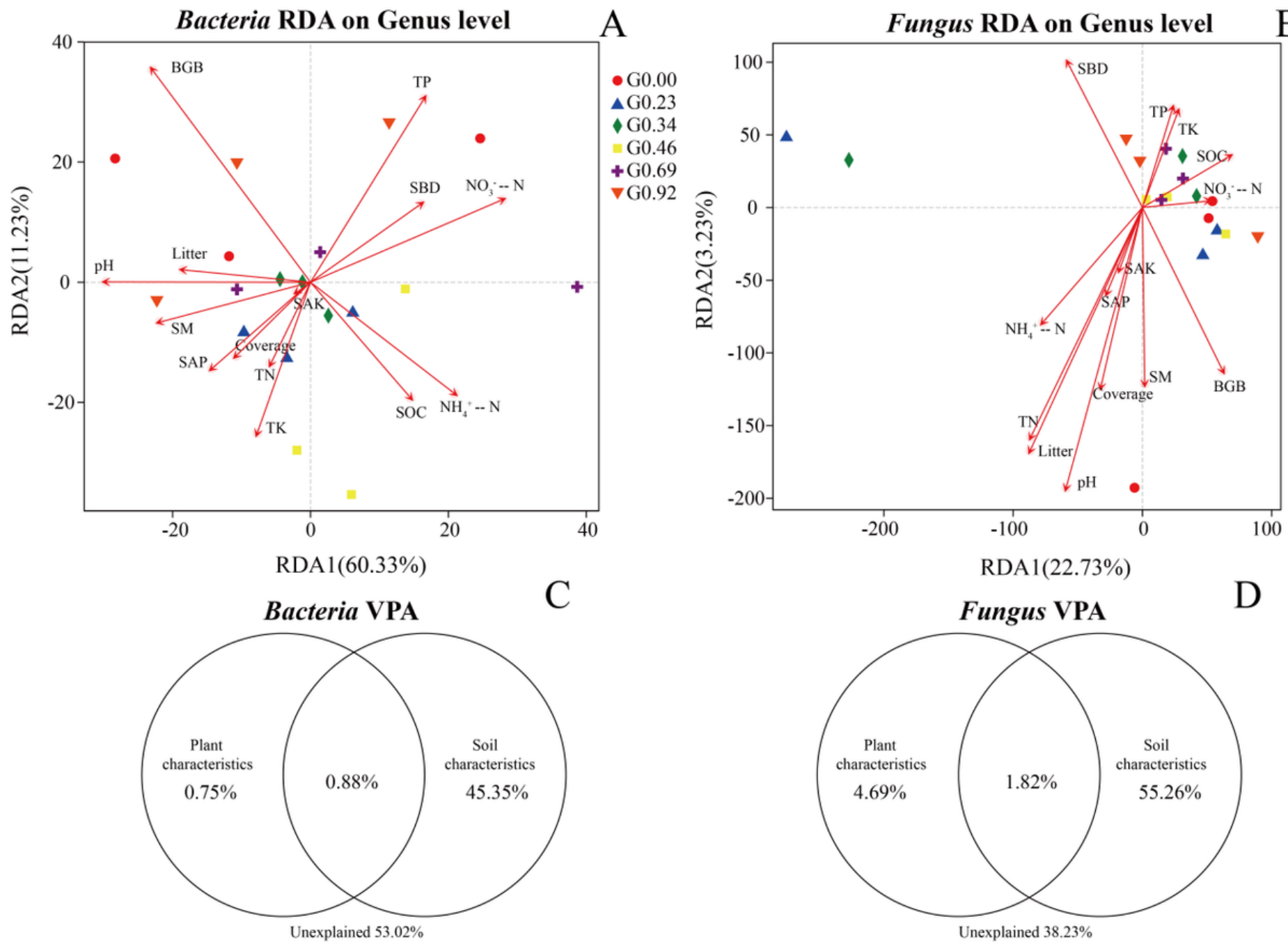

Figure 10 
Redundancy analysis (RDA) of MiSeq data (symbols) and environmental characteristics (arrows). Bacterial and fungal communities are shown in A and B, respectively. The values of axes 1 and 2 are the percentages explained by the corresponding axis. Dots of different colours or shapes in the figure represent groups of samples under different environments or conditions. The red arrows represent quantitative environmental factors, and the length of the arrows of environmental factors represent the impact of environmental factors on species data (interpretation). The angle between the arrows of environmental factors represents positive and negative correlations (acute angle: positive correlation; Obtuse angle: negative correlation; Right angle: no correlation). The distance from the projection point to the origin represents the relative influence of the environmental factors on the distribution of the sample community. Whether the point and the arrow are consistent represents the positive and negative correlation. Analysis of the level of contribution of soil and plant characteristics to changes in bacterial (C) and fungal (D) communities. 